\title{
Research on the Policy Text of Makerspace Space Based on Nvivo: Taking Zhejiang Province as an Example
}

\author{
Yingyan Wang* and Rui Zeng
}

\author{
Yiwu Industrial and Commercial College, Yiwu, China 322000 \\ ${ }^{*}$ Corresponding author. Email: 429874084@qq.com
}

\begin{abstract}
Taking Zhejiang Province's maker space policy as the research object, with the help of nviov software, through the selection of samples, word frequency statistical analysis and coding analysis, the maker space development factor model is constructed. In view of the lack of supporting service system for policy implementation in the construction process of maker space, the government pays more attention to manufacturer space development policy than to efficiency. Finally, the paper proposes to establish a policy supporting service system to improve the service effectiveness of maker space.
\end{abstract}

Keywords: Maker space, Policy, Qualitative research, Grounded theory.

\section{INTRODUCTION}

Policy is the basic tool of governing the country, and public policy is the main means for the state and government to realize their functions. [1] In order to comply with the new trend of mass entrepreneurship and innovation, and further play its supporting role in the national economic development, the State Council of China formulated the document "guidance on the development of mass entrepreneurship space to promote mass innovation and entrepreneurship" in March 2015, which officially kicked off the construction of mass entrepreneurship space. In order to further improve the service level of maker space and promote the new normal development of China's economy, the State Council of China formulated the document "opinions of the State Council on promoting the high-quality development of innovation and entrepreneurship and creating the upgraded version of" entrepreneurship and entrepreneurship "in September 2018, and maker space construction officially entered the high-quality development stage. Driven by the strategic decision-making of innovation driven development in China, provincial governments have successively issued a series of policies to accelerate the development of mass innovation space in various regions and improve the service quality of innovation and entrepreneurship.
In recent years, the research on maker space policy has gradually become a hot topic of government decision-making departments and academia. Different scholars interpret and analyze the maker space policy from different perspectives. Based on the three-dimensional perspectives of policy tools, value attributes and life cycle, Cui (2019) constructs the policy analysis framework of maker space, and points out that the policy system should pay more attention to the coordination and moderation of policies, and pay more attention to the suggestions of stimulating market vitality. [2] From the perspective of policy tools, $\mathrm{Xu}$ (2019) used quantitative research method to analyze 159 public innovation space policy documents according to the research idea of policy type policy time regional city. [3] Professor Lei (2017) used the content analysis method to make a quantitative analysis on the policies related to supporting the development of maker space in Shanghai [4]. Wang (2019) studied the local policy of maker space in Shanghai from the perspective of dependent multi-layer network, formed the supply framework of maker space, and put forward policy suggestions for the development of maker space in Shanghai. Based on the grounded theory, this paper adopts qualitative research method, with the help of nvivo11 qualitative analysis software, through the analysis of 30 policy texts of Zhejiang maker space, summarizes and summarizes continuously, and finally summarizes seven core concepts. On this basis, it 
constructs the maker space development element model and discusses each element. The relationship between them can provide theoretical support for the follow-up research.

\section{SELECTION AND STATISTICAL ANALYSIS OF POLICY TEXTS}

The selected texts of Zhejiang maker space policy are all from public data, which are mainly obtained from the official websites of Zhejiang Provincial People's government, PKULaw and the platform for collection,

Table 1. Zhejiang maker space policy document

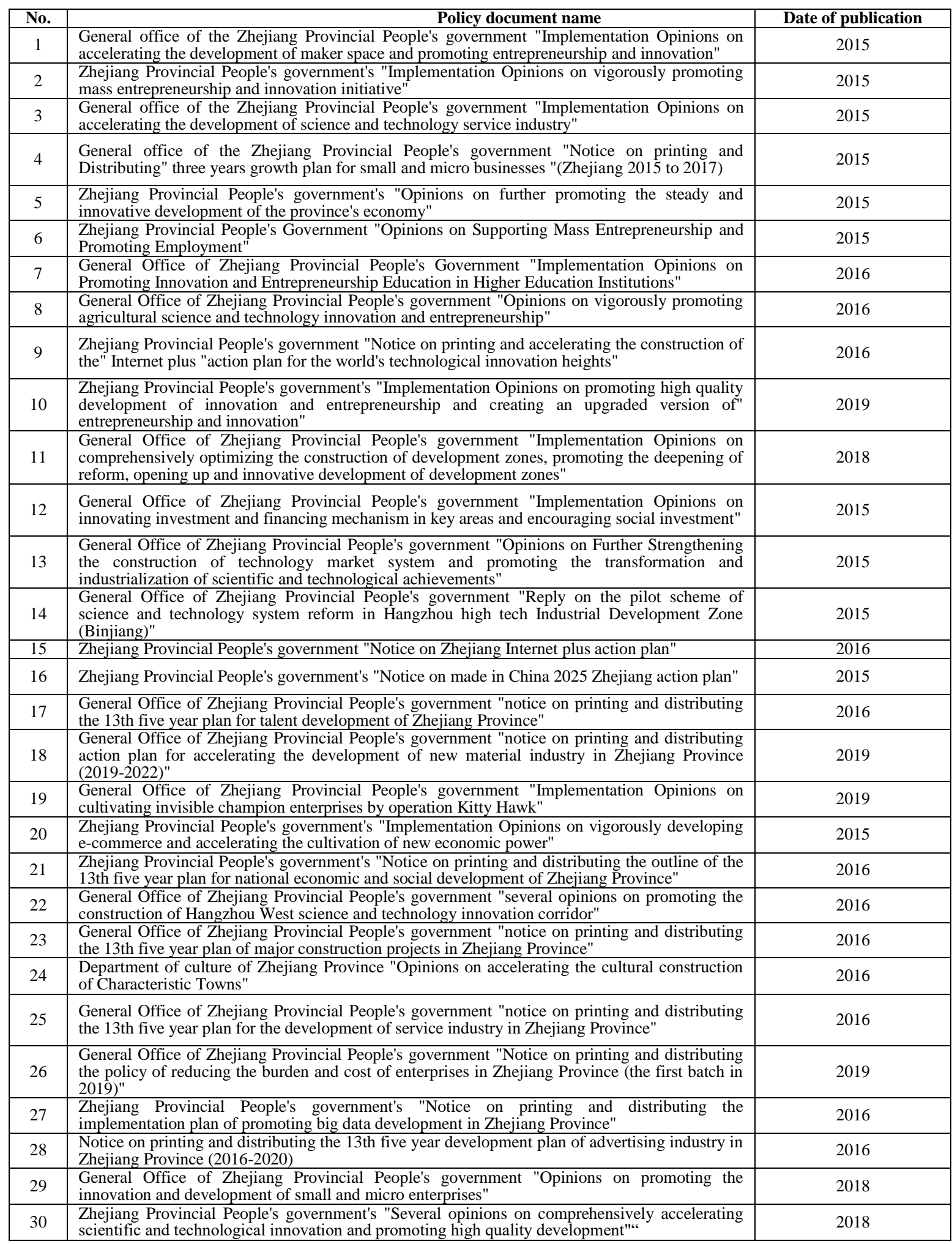


release and interpretation of entrepreneurship and innovation policies. In order to ensure the representativeness, comprehensiveness and accuracy of policy sample selection, the selection principles are determined as follows: first, "maker space" and "innovation and entrepreneurship" are used as policy keywords to search for relevant policies; second, in terms of policy time, the first maker space policy is mainly selected from the guidance of the general office of the State Council on developing maker space and promoting public innovation and entrepreneurship in March 2015 The policy documents are issued to December 2019, which are related to the mass innovation space policy of Zhejiang Province; the third is that the policy-making body is the Zhejiang provincial government and various functional departments; the fourth is that the document types are laws and regulations, plans, schemes, opinions, methods, notices, circulars, etc., which are not included in the informal decision-making documents such as replies, leaders' speeches, work reports, etc. According to the above principles, 30 policy documents of Zhejiang maker space are selected, and the specific policy documents are shown in Table 1.

\section{RESEARCH RESULTS AND ANALYSIS}

\subsection{Statistical Analysis of Word Frequency of Policy Texts}

First of all, the "word frequency" function of nvivo11 software is used to make statistical analysis on the policy documents (see Figure 1). Through the word cloud diagram, the overall situation of crowdsourcing space development policy can be intuitively displayed. The keywords such as "enterprise", "development", "innovation", "construction", "service", "industry", "science and technology", "entrepreneurship" have a large number of names, indicating that they appear more frequently. Innovation and entrepreneurship, enterprise development, scientific and technological innovation, construction of maker space, and service innovation are the key contents that the government pays attention to when formulating maker space development policies, reflecting the main characteristics of maker space development Content, involving the different stages of innovation and entrepreneurship and related elements. "Enterprise" includes small and micro enterprises, high-tech enterprises, e-commerce enterprises and other different types of enterprises, as well as all aspects of financial support for enterprises, so it appears most frequently in policy texts. The related word "development" is a high-frequency word in the text of Zhejiang maker space policy, which indicates that maker space policy takes promoting enterprise development as the core, and also involves industrial development and talent development. "Innovation" includes innovation and entrepreneurship, scientific and technological innovation, and service innovation, which is the essence of the development of maker space, so it appears more frequently in the text. "Service" appeared 1124 times in the policy, indicating that Zhejiang pays attention to innovation and entrepreneurship services. "Science and technology" has appeared 957 times in policy documents, which shows that scientific and technological innovation and scientific and technological talents play an important role in the development of mass innovation space. It also shows that competent departments at all levels play an extremely important role in technological innovation, personnel training and service after talent introduction. The cultivation of service innovation and entrepreneurship talents and the development of maker space have always been the focus of attention in economically developed cities. Strengthening service construction is an important way to improve the service quality of maker space.

Although the effect of word frequency statistics is intuitive, it can only roughly reflect the policy trend. In order to accurately judge, we need to use the "node" function to deeply code and analyze the policy text.

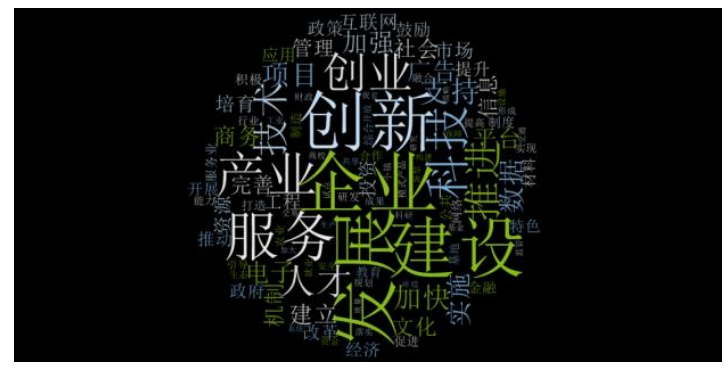

Figure 1. The cloud of words

\subsection{Data coding analysis and model construction}

\subsubsection{Open Coding Access to Direct Elements of Maker Space Development Policy}

In order to better analyze the policy text, this paper, based on the "localization" principle of grounded theory, carries on the open coding to the documents. 30 texts of maker space development policy were imported into nvivo11 software for sentence by sentence analysis and coding. Firstly, the policy document is coded into 686 free nodes, which are located at the bottom of the subordination relationship and are the direct factors influencing the maker space.

\subsubsection{Principal Axis Coding: Building the Development Element Model of Maker Space}

Through the analysis and node coding of the 30 policy documents collected, we have obtained the node structure of Zhejiang maker space development policy 
at all levels. Based on the theory of innovation elements, A structural model of the development elements of crowdsourcing space is formed, as shown in Figure 2.

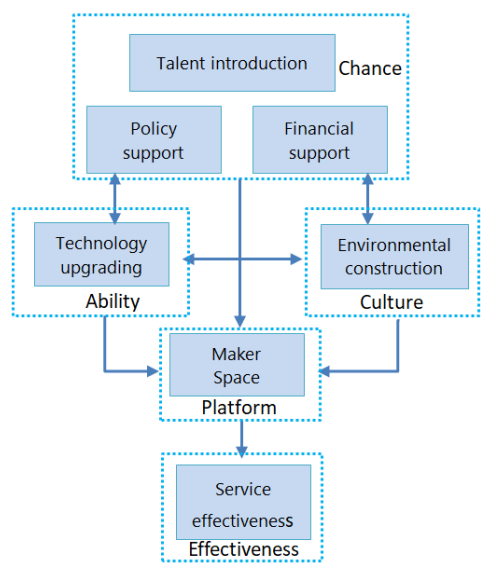

Figure 2. Development element model of maker space

Ability. Competence refers to the comprehensive innovation and entrepreneurship capabilities of the entire organization, such as technological and business knowledge and capabilities such as achievement transformation capabilities, information technology application capabilities, and technology research and development capabilities. In the process of innovation and entrepreneurship, technological innovation is the most valuable core competitiveness. Promote the technological innovation and construction of maker space, which is directly reflected in the effectiveness of maker space's social services. Innovation and entrepreneurship opportunities have a positive effect on innovation and entrepreneurship capabilities, and innovation and entrepreneurship capabilities are the prerequisite for identifying entrepreneurship opportunities.

\section{MODEL RELATIONSHIP ANALYSIS}

\subsection{Ability is the Core Force to Promote the Development of Maker Space}

The essence of maker space is to promote entrepreneurship and technological development, and technological advancement is an essential element in the development of maker space. Sorting by the number of reference points of secondary node coding includes information technology support, enterprise development, transformation of scientific and technological innovation achievements, technology research and development, green manufacturing, and the development of emerging industries (see Table 2). With the advent of Open Innovation 2.0, information technology has attracted much attention. In the "Several Opinions of the People's Government of Zhejiang Province on Comprehensively Accelerating the Development of the Quality of Science and Technology Innovation Promotion Draft", it is proposed to promote the application and integration of information technology in various industries. Therefore, the information technology support node The number of references is the largest, reaching 43. A new round of innovation driven by digital technology and "Internet +" has given birth to new technology research and development, realizing the transformation of scientific and technological achievements, and promoting the development of enterprises. The emerging industries characterized by green and intelligence are focusing on Shape the competitive landscape and enhance economic competitiveness. The adjustment of economic structure under the background of "mass entrepreneurship and innovation" has been realized, a new engine of development has been created, and a new driving force for development has been enhanced.

\section{CONCLUSION}

Maker space is an innovation and entrepreneurship service platform, and its ultimate goal is to achieve value co creation among multiple subjects. The development and value realization of maker space are closely related to the development policy of maker space. Through the analysis of policy documents, combined with the innovation element theory, this paper constructs and explains the development element model of maker space. Through the lack of supporting service system in the current policy implementation of maker

Table 2. Statistical table of support policy codes for elements of maker space capability

\begin{tabular}{|c|c|c|c|}
\hline $\begin{array}{c}\text { Parent } \\
\text { node }\end{array}$ & Secondary level node & $\begin{array}{l}\text { Coding } \\
\text { reference } \\
\text { points }\end{array}$ & Third level node \\
\hline \multirow{9}{*}{$\begin{array}{c}\text { Technology } \\
\text { upgrading } \\
(153)\end{array}$} & Industrial Development & 21 & \multirow{9}{*}{$\begin{array}{l}\text { Develop the service industry, enhance the } \\
\text { competitiveness of enterprises, cultivate new material } \\
\text { leaders, enterprises to carry out innovation, develop } \\
\text { e-commerce, encourage the development of rural } \\
\text { e-commerce, develop e-commerce enterprises, } \\
\text { cultivate high-tech small and medium-sized } \\
\text { enterprises, develop tourism, cultivate high-tech } \\
\text { enterprises, and promote Upgrade of the main body of } \\
\text { small and micro enterprises, development goals of } \\
\text { science and technology enterprises }\end{array}$} \\
\hline & Enterprise Development & 28 & \\
\hline & Technology R \& D & 25 & \\
\hline & $\begin{array}{l}\text { Transformation of scientific } \\
\text { and technological innovation }\end{array}$ & 26 & \\
\hline & Green manufacturing & 10 & \\
\hline & $\begin{array}{l}\text { Information Technology } \\
\text { Support }\end{array}$ & 43 & \\
\hline & Policy measures & 15 & \\
\hline & System reform & 25 & \\
\hline & Simplify the process & 16 & \\
\hline
\end{tabular}


space, this paper puts forward policy suggestions on establishing policy supporting service system and improving the service effectiveness of maker space.

\section{MAIN PROBLEMS AND SUGGESTIONS}

In order to promote the good development of maker space and form a good atmosphere for mass entrepreneurship and innovation. Zhejiang Province has issued a series of supportive policies to help the development of maker space, but there are also some problems. Combined with the coding analysis of the policy text, this paper puts forward policy suggestions for the main problems existing in the development policy of maker space.

Main problem: The policy implementation lacks a supporting service system, and the government pays more attention to investment than effectiveness in the development policy of maker space.

In order to promote the development of maker space, the state and local governments have issued a series of policies and measures to encourage all sectors of society to participate in maker space construction. China's maker space has entered a situation of rapid growth and blooming. However, in the process of rapid development of maker space, there are still problems such as insufficient number of maker space with scale, brand quality and profitability. Through the analysis of the policy documents of maker space in Zhejiang Province, it is found that the government pays less attention to the brand building, marketing service mode and service standard system of maker space, which is due to the lack of corresponding supporting service policies. For example, the national and local government's "opinions on supporting public entrepreneurship and promoting employment" put forward a series of incentive measures to encourage professional and technical personnel in Colleges and universities, scientific research institutions and other institutions to start their own businesses, such as leaving their jobs without pay, enjoying the same title evaluation and promotion, which has great attraction. However, from the current implementation effect, it is not ideal. Even the researchers with entrepreneurial intention are in a wait-and-see state. The reason is that the supporting services for policy implementation are not in place, leading to the prospective entrepreneurs in the system looking forward and backward. For another example, in 2008, the central government promulgated the "opinions on the implementation of the plan for the introduction of overseas high-level talents" (referred to as the "thousand talents plan"), but there are still very few talents returning to China for development.
Policy suggestions: Establish policy supporting service system to improve the service effectiveness of maker space.

We should develop a precise investment mechanism from a global perspective. In 2020, the National People's Congress and the National People's Congress proposed to focus on people's livelihood and employment issues, and the protection of people's livelihood and employment must stabilize the development of small and medium-sized enterprises, so it is necessary to increase investment support. Investment in innovation and entrepreneurship involves all aspects of the in-depth development of the crowd-creation space, such as the introduction and training of talents, and investment in technological innovation. "Investment" under the new crown pneumonia epidemic should be scientifically planned, accurately diagnosed and accurately classified under the guidance of the country's makers' space development policy, and adopt different investment measures according to different types of talents and maker spaces.

\section{ACKNOWLEDGMENTS}

The paper supported by Zhejiang soft science research program: Research on the driving mechanism and performance evaluation of policy guiding innovation elements to mass Innovation: Zhejiang demonstration. Grant No. 2019C35050

\section{REFERENCES}

[1] $\mathrm{Xu}$ Xiaozhou. Theoretical construction of localization based on empirical empirical research - comment on "Research on Localization of Chinese Educational Policy Process"[J]. Educational Development Research, 2017(05): 83-84.

[2] Cui Xiangmin. A textual analysis of the crowd-creation space policy based on a three-dimensional perspective $[\mathrm{J}]$. Science and Technology Management Research, 2019 (17): 30-36.

[3] Xu Shibo. Research on the development policy of crowd-creation space from the perspective of policy tools $[\mathrm{J}]$. Forum on Science and Technology in China, 2019(06): 29-39.

[4] Lei Lianghai, Jia Tianming. Research on the Development Policy of Shanghai Crowd Innovation Space [J]. Shanghai Economic Research, 2017(03): 32-39. 